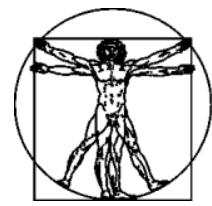

\title{
ПОДВИЖНОСТЬ ДЕНТАЛЬНЫХ ИМПЛАНТАТОВ: НОВЫЕ ВОЗМОЖНОСТИ ИЗВЕСТНОГО ПРИБОРА
}

\author{
В.А. Ерошин ${ }^{1}$, М.В. Джалалова ${ }^{1}$, А.В. Бойко ${ }^{1}$, \\ С.Д. Арутюнов ${ }^{2}$, А.Г. Степанов ${ }^{2}$, А.Н. Даов ${ }^{2}$ \\ ${ }^{1}$ Научно-исследовательский институт механики МГУ имени М.В. Ломоносова, Россия, 119192, Москва, \\ Мичуринский проспект, 1, e-mail: margarita-vd@mail.ru \\ ${ }^{2}$ Московский государственный медико-стоматологический университет имени А.И. Евдокимова, 127473, \\ Москва, ул. Делегатская, 20/1, e-mail: stepanovmd@list.ru
}

\begin{abstract}
Аннотация. Исследовались классические винтовые дентальные имплантаты фрирмы Conmet (Россия) и мини-имплантаты фрирмы 3M ESPE (США), закрепленные в аналогах костной ткани из липы и полиуретана, имеющие различные геометрические параметры. Для мониторинга стабильности дентальных имплантатов с момента их установки, уровня остеоинтеграции и определения допустимых функциональных нагрузок, особенно в начальный период их использования как искусственных опор для зубных и челюстных протезов, используются приборы Periotest (Medizintechnik Gulden, Германия) и Osstell Mentor (Швеция). Благодаря постоянному техническому совершенствованию удалось значительно улучшить последние версии этих приборов (Periotest M и Osstell ISQ), хотя предыдущие версии содержали ряд недостатков. Здесь необходимо подчеркнуть, что результаты измерения прочности крепления в костной ткани оба прибора дают в некоторых условных единицах, не имеющих фризического смысла, поэтому рекомендации, которые даются на основе только этих измерений, недостаточно обоснованы и убедительны. В данной работе проведено исследование последней версии прибора Periotest $M$ и дана интерпретация измеряемых этим прибором параметров как коэффицциентов демпфирования. Для достижения бо́льшей точности предложена методика измерения этих коэффрициентов через специальное устройство для определения подвижности зубов или имплантатов. В численном эксперименте методом конечных элементов получено распределение вертикальных перемещений дентального имплантата с использованием виртуальной модели натурного стенда, которое хорошо согласуется с фризиеским экспериментом. По результатам лазерного тестирования и численного эксперимента получена простая линейная зависимость между коэффициентами демпфирования и податливости, позволяющая для данного дентального имплантата, закрепленного в аналоге костной ткани, на основании показаний прибора Periotest $M$ определять величину его перемещения в зависимости от продольных и поперечных нагрузок.
\end{abstract}

Ключевые слова: ортопедическая стоматология, дентальный имплантат, дентальный мини-имплантат, коэффицциенты демпфирования, коэффрициенты податливости.

(C) Ерошин В.А., Джалалова М.В., Бойко А.В., Арутюнов С.Д., Степанов А.Г., Даов А.Н., 2015 Ерошин Владимир Андреевич, д.ф.-м.н., профессор, в.н.с. НИИ механики, Москва Джалалова Маргарита Васильевна, к.ф.-м.н., с.н.с. НИИ механики, Москва Арутюнов Сергей Дарчоевич, д.мед.н., профессор, заведующий кафедрой клинической стоматологии № 2, Москва

Степанов Александр Геннадьевич, к.мед.н., доцент кафедры клинической стоматологии № 2, Москва Даов Азамат Назарович, ассистент кафедры клинической стоматологии № 2, Москва 


\section{ВВЕДЕНИЕ}

Ортопедическая стоматологическая реабилитация пациентов с применением дентальных имплантатов прочно обосновалась в ежедневной амбулаторнополиклинической практике врача-стоматолога. Появление мини-имплантатов, в частности малоинвазивного протокола их установки, значительно расширило число сторонников использования дентальных имплантатов как среди врачей-стоматологов, так и их пациентов. Однако для успешного проведения подобных операций необходимо проводить мониторинг стабильности дентальных имплантатов с момента их установки и коррекцию допустимых функциональных (жевательных) нагрузок, особенно актуальную в начальный период их использования как искусственных опор для зубных и челюстных протезов.

В настоящее время с этой целью наиболее широко используются приборы Periotest (Medizintechnik Gulden, Германия) и Osstell Mentor (Швеция). Благодаря постоянному техническому совершенствованию удалось значительно улучшить последние версии этих приборов (Periotest $M$ и Osstell ISQ), хотя предыдущие версии содержали ряд недостатков [2]. Здесь необходимо подчеркнуть, что результаты измерения прочности крепления дентальных имплантатов в костной ткани оба прибора дают в некоторых условных единицах, не имеющих физического смысла, поэтому рекомендации, которые даются на основе только этих измерений, недостаточно обоснованы и убедительны. Что касается прибора Osstell ISQ, то последние исследования позволяют значительно расширить его возможности и установить связь между коэффициентами стабильности имплантатов и коэффициентами жесткости крепления дентальных имплантатов в костной ткани, измеряемыми по методике лазерного тестирования $[1,3]$. Все это позволяет описать зависимости между нагрузками, действующими на имплантаты при жевании, и соответствующими им перемещениями.

В данной работе проведено исследование последней версии прибора Periotest $M$ и дана интерпретация измеряемых этим прибором параметров как коэффициентов демпфирования. Установлена связь между ними и коэффициентами податливости, определенными по результатам лазерного тестирования и численного эксперимента.

\section{МАТЕРИАЛЫ, ПРИБОРЫ И МЕТОДЫ ИЗМЕРЕНИЯ}

При проведении исследований использовались классические винтовые дентальные имплантаты фирмы Conmet (Россия) и мини-имплантаты фирмы $3 M$ ESPE (США) (рис. 1), закрепленные в аналогах костной ткани из полиуретана и липы. Для измерения коэффициентов демпфирования дентальных имплантатов, закрепленных в аналогах костной ткани, использовался прибор Periotest $M$ фирмы Medizintechnik Gulden (Германия). Податливость крепления имплантатов определялась на установке по измерению коэффициентов жесткости [2]. Сведения о размерах имплантатов и их массе приведены в табл. 1 , где $l$ - длина имплантатов (в скобках - длина резьбовой части), $d$ - наибольший диаметр, $m$ - масса.

Метод периотестометрии был предложен W. Shulte в 1985 г. для оценки состояния периодонта естественных зубов $[4,5]$ и лишь потом стал использоваться при оценке прочности крепления дентальных имплантатов. В основе методики измерения лежит корреляция между плотностью костной ткани в окрестности дентального имплантата и ее демпфирующими свойствами при ударной нагрузке $[4,5]$. Возбужденный при ударе импульс (рис. 2) проходит по дентальному имплантату и передается костной ткани. Форма и продолжительность отраженного сигнала, зависящая от упругих свойств костной ткани, анализируется с помощью 
микропроцессоров, и на экране дисплея дается интегральная цифровая оценка ее амортизирующей (демпфирующей) способности. Рекомендации для пользователей прибора Periotest даны в табл. 2.

Отметим, что наряду с коэффициентами демпфирования при поперечном ударе (рис. 2) прибор Periotest позволяет определять и коэффициенты демпфирования при продольном ударе, когда дентальные имплантаты нагружаются вдоль оси симметрии. Ниже будет показано, что оба эти коэффициента хорошо согласуются с соответствующими коэффициентами податливости, определяемыми численно и по методике лазерного тестирования.

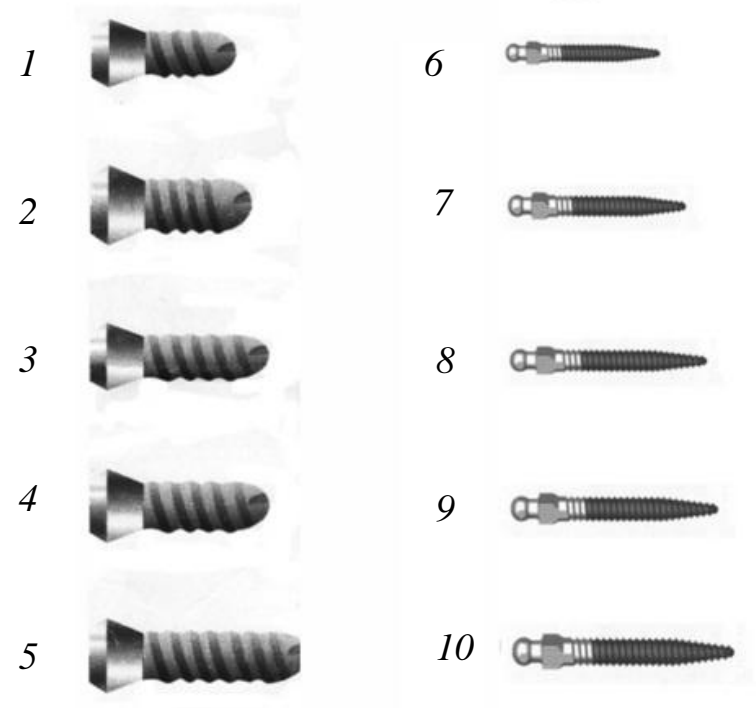

Рис. 1. Форма дентальных имплантатов фирмы Conmet (Россия) (1-5) и мини-имплантатов фирмы $3 M$ ESPE (США) (6-10)

Параметры различных имплантатов

Таблица 1

\begin{tabular}{|c|c|c|c|}
\hline Номер & $l$, мм & $d$, мм & $m, \Gamma$ \\
\hline 1 & $11,0(8)$ & 3,3 & 0,250 \\
\hline 2 & $13,0(10)$ & 4,0 & 0,440 \\
\hline 3 & $15,0(12)$ & 3,5 & 0,400 \\
\hline 4 & $15,0(12)$ & 4,0 & 0,520 \\
\hline 5 & $19,0(16)$ & 4,0 & 0,670 \\
\hline 6 & $14,0(9)$ & 1,7 & 0,120 \\
\hline 7 & $14,3(9)$ & 2,3 & 0,130 \\
\hline 8 & $14,6(10)$ & 2,4 & 0,150 \\
\hline 9 & $21,0(15)$ & 2,4 & 0,255 \\
\hline 10 & $21,0(15)$ & 2,4 & 0,255 \\
\hline
\end{tabular}




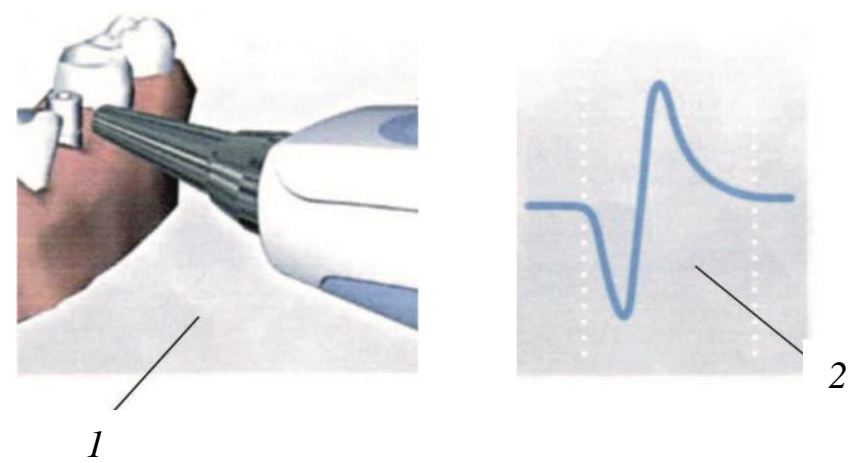

Рис. 2. Измерение коэффициента демпфирования (1)

и форма отраженного сигнала (2)

Впервые сравнение коэффициентов демпфирования с коэффициентами жесткости было проведено в работе [2], где отмечалось удовлетворительное качественное соответствие этих результатов. Однако судить о количественном соответствии было трудно, так как с увеличением прочности крепления дентальных имплантатов в костной ткани коэффициенты жесткости растут, а коэффициенты демпфирования убывают и даже становятся отрицательными (см. табл. 2). Поэтому в дальнейшем для получения более ясной картины вместо коэффициентов жесткости дентальных имплантатов были введены коэффициенты податливости П как отношение перемещения точки нагружения дентальных имплантатов к величине приложенной силы: $\Pi=\Delta / F$, где $\Delta-$ перемещение точки приложения нагрузки к дентальным имплантатам, мкм; $F$ - величина силы. На рис. 3 приведена схема измерения перемещения $\Delta$ при поперечном нагружении имплантата.

Таблииа 2

Рекомендации для пользователей прибора Periotest

\begin{tabular}{|c|c|}
\hline $\begin{array}{c}\text { Диапазон значений } \\
\text { Periotest }\end{array}$ & Интерпретация \\
\hline$-8-0$ & $\begin{array}{c}\text { Хорошая остеоинтеграция - имплантат хорошо } \\
\text { интегрирован и может подвергаться нагрузке }\end{array}$ \\
\hline $1-9$ & $\begin{array}{c}\text { Требуется клиническое обследование - в большинстве } \\
\text { случаев нагрузка на имплантат (пока) невозможна }\end{array}$ \\
\hline $10-50$ & $\begin{array}{c}\text { Остеоинтеграция недостаточна - имплантат не должен } \\
\text { подвергаться нагрузке }\end{array}$ \\
\hline
\end{tabular}

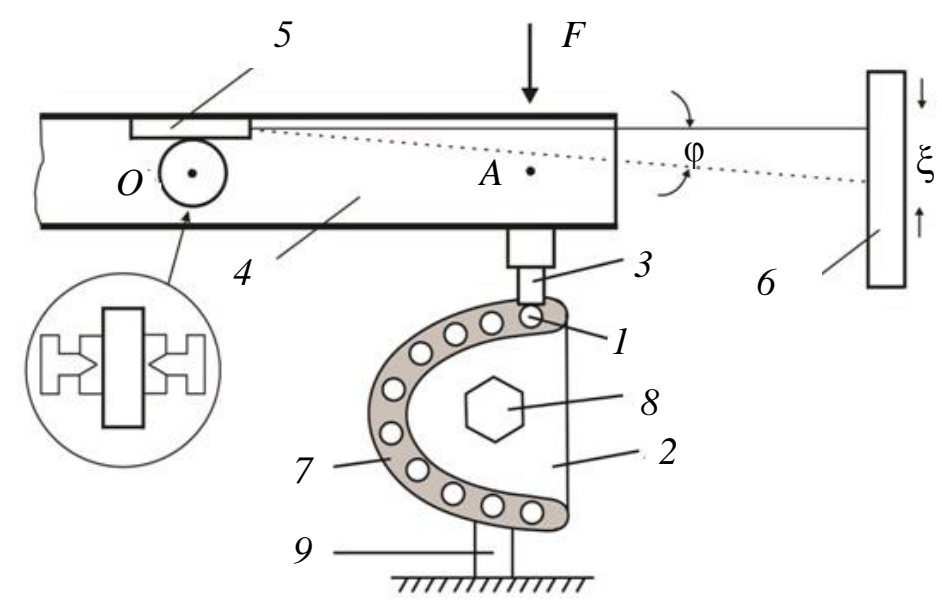

Рис. 3. Схема измерения перемещения при поперечной нагрузке 
Здесь 1 - дентальные мини-имплантаты; 2 - аналог костной ткани; штифт 3, опирающийся на сферическую головку дентального мини-имплантата, жестко соединенного с рычагом 4, вращающимся вокруг оси, проходящей через точку $O$, нагружается силой $F$, при этом точка падения луча лазера 5 , закрепленного на рычаге $O A$, совершает перемещение $\xi$ на экране $6 ; 7$ - каппа с отверстиями; 8,9 - элементы крепления аналога костной ткани. Величина угла поворота ф рычага $O A$ и вертикальное перемещение сферической головки имплантата $\Delta$ определяются по формулам $\varphi=\xi / L$, $\Delta=\varphi \cdot O A$, где $L$ - расстояние от центра вращения рычага $O$ до экрана $(\xi<<L)$.

Как уже отмечалось ранее, разброс результатов измерения при использовании предыдущих версий прибора Periotest был довольно большим. В последней версии прибора этот недостаток в значительной степени удалось преодолеть за счет изменений в программном обеспечении. Однако в некоторых случаях необходима более высокая точность измерения, что связано с рядом недостатков методики проведения исследования. Это обусловлено прежде всего наличием человеческого фактора: невозможно избежать физиологического тремора рук исследователя, контролировать точность места воздействия датчика, причем расстояние между датчиком и вестибулярной поверхностью зуба (или центром абатмента дентальных имплантатов) должно составлять 2 мм, а ось датчика направлена строго перпендикулярно к поверхности зуба.

Для достижения этой цели была предложена методика измерения коэффициентов демпфирования через специальное устройство для определения подвижности зуба или имплантата (решение о выдаче патента РФ по заявке № 2014122750 от 04.06.14). Это устройство представляет собой прозрачную каппу, по форме соответствующую индивидуальным особенностям анатомии зубных рядов установленных имплантатов и альвеолярных челюстей пациента. Изготавливается каппа из жесткой пластмассы толщиной 4 мм методом вакуумного термопрессования. По периметру между поверхностью каппы и исследуемыми зубами имеется зазор в 2 мм, а в проекции центра клинического экватора вестибулярной поверхности исследуемых зубов в каппе сформированы конусные сквозные отверстия, конусность которых соответствует конусности сопла датчика измерительного прибора.

Эксперименты показали, что при проведении мониторинга подвижности дентальных имплантатов через отверстия в каппе удары наконечника прибора происходят единообразно в одной и той же точке и под необходимым углом к имплантату, т.е. эта методика действительно уменьшает разброс результатов измерения и является достаточной эффективной.

Таблицча 3

Значения коэффициентов демпфирования и податливости дентальных имплантатов, закрепленных в различных аналогах костной ткани (№ п/п - номер дентального имплантата)

\begin{tabular}{|c|l|c|c|c|c|c|c|c|c|c|c|}
\hline № п/п & Коэффициенты & 1 & 2 & 3 & 4 & 5 & 6 & 7 & 8 & 9 & 10 \\
\hline \multirow{2}{*}{$\mathrm{I}$} & $P$ & $-3,0$ & $-4,1$ & $-2,2$ & $-6,7$ & $-6,7$ & $-0,2$ & 0,1 & 0,6 & 4,0 & 6,3 \\
\cline { 2 - 12 } & П, мкм/H & 4,8 & 4,6 & 6,3 & 2,7 & 1,9 & 4,2 & 5,1 & 5,6 & 10,0 & 8,4 \\
\hline \multirow{2}{*}{$\mathrm{II}$} & $P$ & 11,1 & 9,0 & 7,9 & 9,2 & 7,5 & 14,3 & 13,3 & 14,1 & 14,5 & 15 \\
\cline { 2 - 12 } & П, мкм/H & 13,0 & 10,1 & 11,0 & 9,9 & 8,1 & 12,9 & 12,7 & 13,2 & 13,1 & 13,5 \\
\hline \multirow{2}{*}{$\mathrm{III}$} & $P$ & 36,9 & 35,2 & 35,2 & 34,8 & 32,6 & 32,3 & 32,0 & - & - & - \\
\cline { 2 - 11 } & П, мкм/H & 164 & 127 & 143 & 153 & 112 & 137 & 130 & 165 & 203 & 229 \\
\hline \multirow{2}{*}{$\mathrm{IV}$} & $P$ & $-5,4$ & $-8,0$ & $-8,0$ & $-8,0$ & $-8,0$ & $-7,0$ & $-8,0$ & $-7,5$ & $-8,0$ & $-8,0$ \\
\cline { 2 - 11 } & П, мкм/H & 1,85 & 0,50 & 1,15 & 0,37 & 0,33 & 0,79 & 0,43 & 0,47 & 0,37 & 0,37 \\
\hline \multirow{2}{*}{$\mathrm{V}$} & $P$ & $-0,5$ & $-1,9$ & $-2,3$ & $-2,6$ & $-3,8$ & $-2,0$ & $-1,5$ & 0,9 & 1,1 & 1,0 \\
\cline { 2 - 11 } & П, мкм/H & 4,2 & 4,0 & 3,6 & 3,2 & 2,4 & 3,1 & 3,1 & 4,8 & 5,0 & 5,7 \\
\hline \multirow{2}{*}{$\mathrm{VI}$} & $P$ & 33 & 32 & 31 & 29 & 28 & 28 & 27 & 33 & 35 & 34 \\
\cline { 2 - 10 } & П, мкм/H & 175 & 126 & 147 & 149 & 96 & 114 & 112 & 192 & 207 & 170 \\
\hline
\end{tabular}




\section{СРАВНЕНИЕ КОЭФФИЦИЕНТОВ ДЕМПФИРОВАНИЯ И ПОДАТЛИВОСТИ}

Для сравнения коэффициентов демпфирования $P$, измеряемых прибором Periotest $M$, и коэффициентов податливости П, определяемых по методике лазерного тестирования, было проведено несколько серий экспериментов с использованием дентальных имплантатов (см. рис. 1), закрепленных в различных аналогах костной ткани. Опытные данные приведены в табл. 3 и на рис. 4, где по горизонтальной оси отложены коэффициенты демпфирования, по вертикальной - податливости.

Рассмотрим сначала связь между $P$ и П при поперечных нагрузках (строчки I-III табл. 3). Они показывают, что в области $(-8<P<9)$, т.е. при «хорошей остеоинтеграции» и в случаях, когда «требуется дополнительное клиническое обследование», связь между коэффициентами демпфирования и податливости близка к линейной. Это говорит о целесообразности введения нового значения коэффициента демпфирования по формуле: $P_{\mathrm{H}}=P_{\mathrm{c}}+10$, (где н - новое и с - старое значения). В этом случае получаем следующую связь между коэффициентами податливости и демпфирования: $\Pi=0,57 \cdot P_{\mathrm{H}}$. Таким образом, в наиболее важной части области измерения новый коэффициент демпфирования будет сразу давать представление о прочности крепления дентальных имплантатов. Более того, так как $\Pi=\Delta / F$, после введения нового коэффициента демпфирования с помощью прибора Periotest $M$ можно будет оценить величину перемещения $\Delta$ точки имплантата, находящейся под действием приложенной силы: $\Delta=\Pi \cdot F=0,57 \cdot P_{\mathrm{H}} \cdot F$.

Следовательно, измерения, производимые с помощью прибора Periotest $M$, будут давать информацию не только о ходе процесса остеоинтеграции, но и о подвижности дентальных имплантатов. При $P>10$ (или $P_{\text {н }}>20$ ) прочность крепления дентальных имплантатов быстро убывает и в соответствии c рекомендациями фирмы-производителя они не могут нести функциональные нагрузки.

$\Pi$,

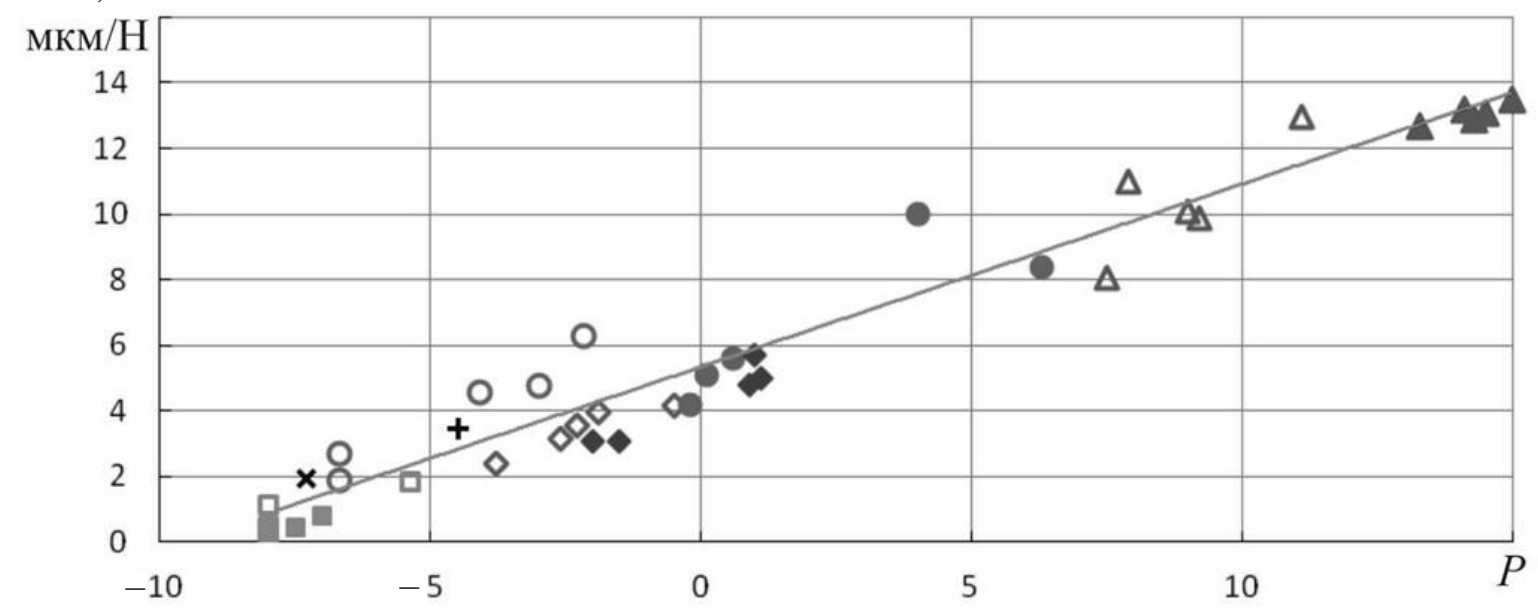

Рис. 4. Зависимость коэффициентов податливости П от коэффициентов демпфирования $P$. Поперечные нагрузки: липа - - классические винтовые дентальные имплантаты, - - дентальные мини-имплантаты; полиуретан $\Delta$ - классические винтовые дентальные имплантаты, $\boldsymbol{\Delta}$ - дентальные миниимплантаты. Продольные нагрузки: липа - - - классические винтовые дентальные имплантаты, ш - дентальные мини-имплантаты; полиуретан - $\diamond$ - классические винтовые дентальные имплантаты, - дентальные мини-имплантаты. Расчет: липа $-\square$; полиуретан - + 
Здесь необходимо отметить, что, несмотря на значительное различие формы имплантатов, разница между значениями коэффициентов подвижности для классических винтовых дентальных имплантатов (точки $1,3,5,7$ - см. рис. 4 и табл. 3) и мини-имплантатов (точки 2, 4, 6, 8) невелика и в пределах точности измерения они практически не отличаются (линия линейной регрессии на рис. 4 для опытных данных, включая продольные нагрузки, получена методом наименьших квадратов, дисперсия $\left.\sigma_{y}^{2}=0,58\right)$.

На рис. 4 приведены также аналогичные опытные данные о связи между коэффициентами демпфирования и податливости при продольном ударе и продольной статической нагрузке (строчки IV-VI в табл. 3). Они показывают, что эти экспериментальные результаты легли на ту же самую кривую, но располагаются ниже, чем при поперечных нагрузках. И это не случайно. Расчеты показывают, что при упругих деформациях аналогов костной ткани перемещения дентальных имплантатов при продольных нагрузках примерно в 2,5 раза меньше, чем при поперечных [3].

Для достоверности результатов, полученных методом лазерного тестирования, были проведены численные расчеты по определению коэффициентов податливости. Рассматривались образцы из липы и полиуретана в форме параллелепипеда размером $48 \times 20 \times 14$ мм с четырьмя ввинченными классическими конструкциями дентальных имплантатов. Фотография натурного образца из полиуретана с имплантатами приведена на рис. 5.

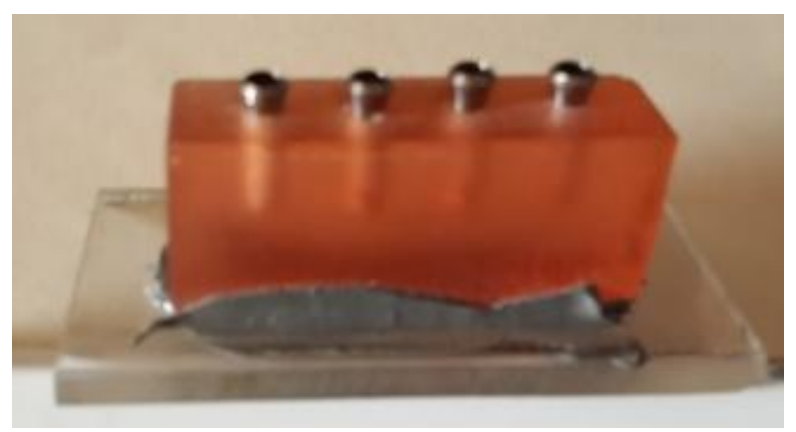

Рис. 5. Фотография натурного образца из полиуретана с ввинченными имплантатами

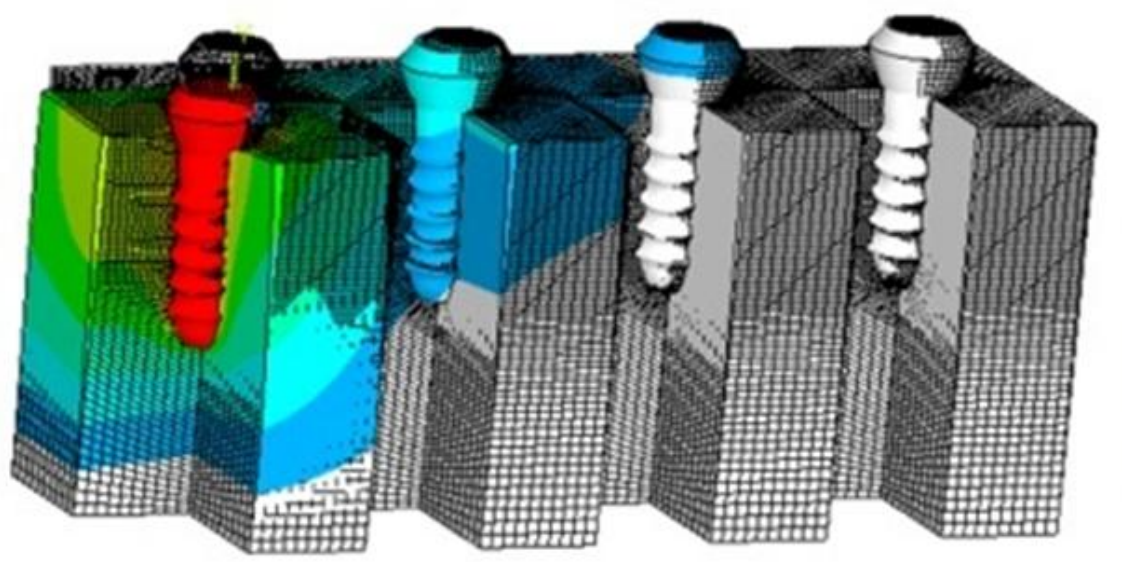

$\Delta=0,010266$

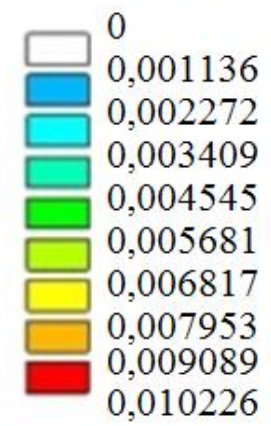

Рис. 6. Распределение перемещений в виртуальной модели (продольная нагрузка приложена на крайний имплантат) 
На рис. 6 показано распределение вертикальных перемещений, полученное в численном эксперименте методом конечных элементов с использованием виртуальной модели натурного стенда. При нагрузке на крайний имплантат $F=5 \mathrm{H}$ его перемещение составило $\Delta=0,010226$ мм $=10,2$ мкм (см. столбец справа на рис. 6). Поскольку $\Pi=\Delta / F$, то 10,2 мкм / $5 \mathrm{H}=2,04$ мкм/Н - это значение отмечено крестиком $(\times)$ на рис. 4 (там же другим крестиком (+) отмечено значение коэффициента податливости П = 3,75 мкм/Н для образца из материала полиуретана).

Для визуализации картины распределения перемещений возле каждого имплантата вырезаны части образца. Прозрачная сетка - это состояние виртуальной модели до нагрузки имплантата (специально выбран утрированный масштаб): хорошо видно перемещение первого имплантата, который слегка потянул за собой и второй имплантат.

\section{ЗАКЛЮЧЕНИЕ}

Проведенные исследования показали, что последняя версия прибора Periotest $M$ может использоваться при оценке уровня остеоинтеграции и готовности дентальных имплантатов к функциональным нагрузкам, так как фирме-изготовителю удалось устранить бо́льшую часть отмеченных ранее недостатков: уменьшена величина ударного импульса (прибор стал менее травматичным) и улучшена повторяемость результатов измерения. Точность и репрезентативность приводимых исследований возможны и достигаются использованием разработанного устройства для определения подвижности зубов. Более того, наши исследования показали, что имеются прекрасные возможности для дальнейшего совершенствования прибора. Введение новой шкалы придаст физический смысл измерениям, позволит оценивать не только готовность дентальных имплантатов к функциональным нагрузкам, но и их несущую способность на основе измерения коэффициентов продольного демпфирования, т.е. сформируется научная база для проведения коррекции допустимых функциональных (жевательных) нагрузок.

\section{СПИСОК ЛИТЕРАТУРЫ}

1. Арутюнов С.Д., Ерошин В.А., Степанов А.Г., Бойко А.В., Даов А.Н., Мацаберидзе Л.Г. Новые тенденции использования дентальных мини-имплантатов // Российский вестник дентальной имплантологии. - 2013. - № 2 (28). - С. 14-20.

2. Ерошин В.А., Арутюнов С.Д., Арутюнов А.С., Унанян В.Е., Бойко А.В. Подвижность дентальных имплантатов: приборы и методы диагностики // Российский журнал биомеханики. - 2009. - Т. 13, № 2. - С. 34-48.

3. Ерошин В.А., Джалалова М.В. Напряженно-деформированное состояние биомеханической системы имплантат - упругое основание // Российский журнал биомеханики. - 2012. - Т. 16, № 3(57). C. $82-95$.

4. Shulte W., Lukas D. The Periotest method // Int. Dent. J. - 1990. - Vol. 42, № 6. - P. 433-440.

5. Shulte W. What is the significance of the Periotest method currently? // Deutsch Zahnarzt Z. - 1985. Vol. 40, № 7. - P. 705-706. 


\section{MOBILITY OF DENTAL IMPLANTS: NEW CAPABILITY OF A KNOWN DEVICE}

\section{V.A. Eroshin, M.V. Dzhalalova, A.V. Boyko, S.D. Arutyunov, A.G. Stepanov, A.N. Daov (Moscow, Russia)}

We used classical screw-type dental implants from the Conmet company (Russia) and miniimplants from the 3M ESPE company (USA) fixed in osseous tissue analogs of polyurethane and linden, having different geometric parameters. Devices Periotest (Medizintechnik Gulden, Germany) and Osstell Mentor (Sweden) are used to monitor the stability of dental implants since its installation, the level of osseointegration and functional determinaton of allowable loads, especially in the initial period of their use as an artificial supports for dental and mandibular prostheses. Due to permanent technical development, the last versions of these devices (Periotest M and Osstell ISQ) have been considerably improved while there were some weak points in previous versions. We must stress that both devices give results of strength measurement for dental implants fastening in osseous tissue in some standard units which have no physical sense, therefore guidelines on the basis of only these measurements are not sufficiently proved and convincing. In this work, the last version of Periotest $\mathrm{M}$ was examined and parameters measured by this device were interpreted as coefficients of damping. Methods for measuring these factors through the special device for determining the mobility of the teeth or implants were proposed to achieve higher accuracy. Distribution of vertical displacements of dental implants obtained in numerical simulations by finite element method using a virtual model of a full-scale test bench is consistent with the physical experiment. A simple linear relationship between damping ratio and compliance based on the results obtained by the laser test and numerical experiment, allowing for the dental implant fixed in the bone analogue, based on readings of Periotest $\mathbf{M}$ to determine the value of its movement, depending on the longitudinal and transverse loads.

Key words: orthopedic dentistry, dental implant, dental miniimplant, coefficients of damping, compliance coefficients.

Получено 21 июня 2015 